\title{
LOS GÉNEROS SATÍRICOS DURANTE EL REINADO DE ALFONSO X EN LA POESÍA GALLEGOPORTUGUESA Y EN OTRAS TRADICIONES LIIRICAS ROMANCES
}

\author{
Santiago Gutiérrez García \\ Universidade de Santiago de Compostela \\ santiaguti@gmail.com
}

Uno de los rasgos que más llaman la atención del cancionero profano de Alfonso X es el predominio absoluto que en él tienen las cantigas satíricas. De las cuarenta y cuatro composiciones que le atribuye su edición crítica más reciente (Paredes 2001: 41), treinta y nueve pertenecen a ese registro -incluyendo cuatro tensones-, por cuatro al de amor y una -de atribución dudosa- al de amigo, junto a dos cantigas de loor -una de ellas asimismo de autoría problemática-. Si a este corpus se le unen las cuatrocientas veintisiete Cantigas de Santa María, se comprobará que el registro amoroso ocupa una posición marginal en lírica alfonsí. Tal panorama puede parecer paradójico, a la vista de que el reinado del monarca castellano coincide con la etapa de esplendor del trovadorismo gallegoportugués, caracterizada por la diversificación de la producción lírica y por el enriquecimiento de formas poéticas previas con nuevos aportes, que procedían de la renovación de las ya existentes o de la importación de nuevos modelos extrapeninsulares.

El corpus profano alfonsí parecería al margen de ciertos movimientos estéticos de la segunda mitad del siglo XIII, como el auge de la poesía popularizante, al que no fue ajeno, sin ir más lejos, Don Dinis, quien cultivó con profusión la cantiga de amigo $-\mathrm{y}$, por extensión, la poesía amorosa-, del mismo modo que fue receptivo a un género de origen foráneo, como la pastorela ${ }^{1}$. Ante la amplitud de los cancioneros individuales de ambos tro-

\footnotetext{
${ }^{1}$ De las ciento treinta y siete cantigas atribuidas a Don Dinis, apenas diez pertenecen a los géneros satíricos, mientras que setenta y seis son cantigas de amor y cincuenta y dos de amigo (Lang 2010).
} 
vadores, para cuya conservación debió de influir su condición regia, parece improbable que el del Rey Sabio sufriese la pérdida de las cantigas amorosas, precisamente aquellas que se tenían por más valiosas. Más aún, Alfonso $\mathrm{X}$ sí se mostró abierto a influencias galorrománicas, pues retomó el esquema métrico musical de una canso de Raimbaut de Vaqueiras $-D$ 'una dona $m$ tueill e'm lais - para una de sus piezas amorosas, Ben sabia eu, mia senhor $(\mathrm{B} 468)^{2}$ o compuso una tensón junto a Arnaut Catalan, Senher, ad-ars ie'us venh' querer (B477), que refleja el grado de familiaridad con que en su corte se acogía la lírica occitana ${ }^{3}$.

La preferencia de Alfonso X por el cultivo de la poesía satírica contradice igualmente los derroteros que en la segunda mitad del siglo XIII parecía tomar dicho registro en ese referente de prestigio que era el trovadorismo provenzal. Asperti (2006: 58-59) llama la atención acerca de la crisis a que estaba sometido el sirventés en esa tradición lírica, el cual había comenzado un declive a mediados de siglo a causa de que su sometimiento a la canso colidía con la creciente valorización del concepto de autoría y de su adscripción al registro satírico, en tanto que poesía de circunstancias. De resultas, estaba cediendo protagonismo en el sistema de géneros a la poesía moral, según muestra la obra de dos autores tardíos vinculados estrechamente con las cortes ibéricas, Cerveri de Girona y Guiraut Riquier, que contribuyeron a la reinterpretación del vers como un género moralizante, después de que en el siglo XII constituyese la forma omnicomprensiva del canto cortés y de que a inicios del XIII no se distinguiese con claridad de la canso $^{4}$. La especialización del vers como poesía moral reflejaba la aspiración de ambos autores a ejercer como consejeros áulicos, para que así se les reconociese como profesionales respetados, distintos de los siempre cuestionados juglares (vid. Cabré 1996).

El ejemplo de Riquier resulta especialmente interesante, no sólo porque en la tradición occitana ocupa un lugar menos marginal que el que corresponde a

\footnotetext{
${ }^{2}$ Paredes (2001: 150-151) retoma la hipótesis de Canettieri y Pulsoni (1994: 17), acerca un conocimiento indirecto de este esquema por parte de Alfonso X, bien gracias a Sordel, como afirman estos autores, bien por medio de Arnaut Catalan o, incluso, a través de la influencia de Moniot de Paris.

${ }^{3}$ Más dudosa es la influencia sobre $O$ genete (B491 / V74) de un modelo transpirenaico, tal y como propone Cantigas de seguir. Según esta base de datos, la pieza alfonsí habría retomado el esquema métrico-musical de Un trichaire de Guilhem de Berguedà. Paredes, sin embargo, sugiere la huella de la lírica mediolatina, quizá por mediación de la obra de Gautier de Coincy, al tiempo que indica la presencia de dicho esquema en otros poetas coetáneos, tanto gallegoportugueses, como occitanos (Paredes 2001: 281282).

${ }^{4}$ Vid., por ejemplo, las definiciones que ofrecen del vers la Doctrina de compondre dictatz -«deus parlar de veritatz, de exemples e de proverbis o de lauzor, no pas en semblant d'amor»-y el Tratado de Ripoll -«es de materia tota moral, de ço qui·s pertayn a nodriment»-(Marshall 1972: 95 y 102).
} 
Cerveri ${ }^{5}$, sino por sus conocidas vinculaciones con Alfonso X, en cuya corte habría permanecido durante unos diez años (Alvar 1977: 240) y en donde compuso la Suplicatio y la Declaratio, con las que aspiraba a clarificar las relaciones entre los diferentes agentes trovadorescos y a definir sus respectivas funciones. Mientras que la Suplicatio censuraba a los trovadores que no sabían ejercer su arte y que cultivaban la poesía mordaz ( «Car mant trobador si / de diverses trobars, / a qui non tanh onrars / car lur fag no sert, / que l'un tenon apert / lurs sabers en dir mal», vv. 810-815; Bertolucci-Pizzorusso 1996: 71), la Declaratio ponía orden en el confuso panorama descrito en la Suplicatio y proponía una jerarquía de agentes trovadorescos que encabezaban los doctores del trovar («Doctors: car doctrinar / sabon ben», vv. 304-305, aquellos que «sabon essenhar / [...] en vers et en cansos / et en autres dictatz / c'avem desus nomnatz», vv. 297-302; ibid.: 105-106). En esta gradación, que sólo admitía «sirventes valens» (v. 359), la poesía satírica no se consideraba digna del ambiente cortesano.

Sin embargo, la propia producción del monarca castellano muestra la distancia que separa las formulaciones teóricas y la praxis, pero también como en períodos de cambios de paradigma -y el auge de la poesía moral obligaba a un reajuste de todo el sistema genérico de la lírica- se produce la convivencia prolongada de propuestas conservadoras e innovadoras, a menudo en aparente contradicción. El cultivo de las cantigas morales gallegoportuguesas corroboraría tal afirmación. Todos sus autores florecen durante la segunda mitad del siglo XIII, en coincidencia con la época de esplendor del reinado alfonsí, aunque con cierta tendencia a agruparse hacia el final de ese arco cronológico. Junto al propio Alfonso X, que se incluye entre estos autores por Non me posso pagar tanto (B480 / V63), tanto Fernan Soarez de Quinhones, como Pero Mafaldo, Gil Perez Conde, que prolongaría su actividad hasta 1295, o Airas Nunes, quien escribe ya durante el reinado de Sancho IV, se ubican dentro del tercer cuarto de siglo. No parece casual, de todas formas, que la actividad literaria de Martin Moxa, el autor que con más insistencia compuso cantigas morales -hasta cuatro poesías, por una el resto de cultivadores-, se desarrollase en los últimos años de ese siglo.

Ahora bien, los análisis estadísticos realizados por Paden (1997) arrojan luz sobre la evolución de los géneros del trovadorismo ibérico. Este autor

${ }^{5}$ De ahí que sus composiciones estén mejor representadas que las de Cerveri en algunos de los cancioneros occitanos más importantes, como $C$ y $R$ (Asperti 2006: 30).

${ }^{6}$ Las cuatro cantigas de Martin Moxa son: B889 / V473, B915 / V502, B887 / V471 y B896 / V481. Del resto de autores con este tipo de cantigas se conserva sólo una pieza: V592-593 de Pero Gomez Barroso, B1525 de Gil Perez Conde, B871 / V475 de Airas Nunez, B1557 de Fernan Soarez de Quinhones y B374 de Pero Mafaldo. 
divide el devenir histórico de la lírica gallegoportuguesa en tres fases de cuarenta y cinco años: los inicios (1200-1244), la época alfonsí o de esplendor (1245-1289) y la dionisina (1290-1325). Una visión de conjunto muestra que las cantigas satíricas se manifiestan de forma muy tímida en el primer período y que su eclosión no se produce hasta mediados de siglo. Alcanzan entonces un auge que las equipara en producción a las cantigas amorosas y las consolida, hasta el punto de que mantienen su protagonismo en la fase final, a pesar de cierto retroceso. Más aún, entre 1300-1339 la sátira es el registro más cultivado, en un último repunte que cubre el treinta y nueve por ciento de la producción de esos años, frente a su decaimiento en el último tercio del siglo XIII, cuando había bajado al dieciocho por ciento. Con todas las limitaciones que ofrece -entre ellas, que obvia el período posdionisino-, el análisis de Paden ayuda al trazado de las grandes corrientes evolutivas de la lírica peninsular. $Y$ en ellas lo que se aprecia es un agotamiento relativo de la cantiga de amor, que tras una fase primera de dominio, con el setenta y siete por ciento de la producción, cedió ante los otros géneros desde mediados de siglo, lo cual reflejaría así la diversificación lírica que se suele atribuir al reinado alfonsí y asimismo explicaría, al menos en parte, el retraimiento de la cantiga de amor en la producción del Rey Sabio.

Lo más llamativo de esas estadísticas, con todo, es su grado de coincidencia con las que el mismo autor elaboró para la lírica occitana (2000). En esta tradición poética, en efecto, tanto la sátira -aunque la etiqueta de sirventés, que emplea en este caso, sobrepasa el registro satírico - como la poesía amorosa recorren un camino análogo al que trazaban en el trovadorismo ibérico. Esta segunda, sin ir más lejos, se consolida a mediados del siglo XII y se afirma como el género más abundante con diferencia hasta la tercera década del XIII. Entonces empieza su declive, que coincide con la consolidación de otros géneros, como el sirventés, la cobla o los géneros menores. En la lírica d'oc, pues, y salvadas las distancias con la situación de la gallegoportuguesa, se advierte de nuevo un agotamiento de la canción de amor, que permitiría la apertura del discurso del lirismo cortés a otras propuestas y registros.

Es aquí donde habría que situar el auge de la poesía satírica que tiene lugar en la Península durante los años centrales del siglo XIII -ajeno aún a la competencia de la poesía moral-, coincidiendo con el reinado alfonsí. Por más que llame la atención el desequilibrio entre los diversos géneros que revela el cancionero profano del Rey Sabio, no por ello deja de integrarse en un movimiento más amplio, extensible al conjunto de la Romania, que llevó

\footnotetext{
${ }^{7}$ Así, por ejemplo, el sirventés occitano incluye poemas de tono moral, mientras que para la lírica gallegoportuguesa Paden (1997) incluye estos últimos entre los géneros menores.
} 
a la sátira a ocupar un lugar destacado en las compilaciones cancioneriles de ese siglo. Hasta el punto de que Rossi (2002: 38) cita al monarca castellano entre otros cultivadores coetáneos «del comico e del burlesco», tal que Peire Cardenal, Cecco Angiolieri, Rustico Filippi, Adam de la Halle o Rutebeuf, protagonistas todos ellos del aludido apogeo de los géneros satíricos. Es por eso que resulta tan adecuado un análisis comparatista de las diversas tradiciones líricas románicas, en el que se refleje la estructura del sistema literario del Occidente medieval como una red conformada por cortes y -en las zonas de densa urbanización, como Italia o el norte de Francia- ciudades, cuyas interrelaciones superaban las divisiones lingüísticas y políticas. En este entramado la corte de Alfonso X, antes que por su situación periférica o sus peculiaridades, destaca como participante en las grandes corrientes estéticas e ideológicas de su tiempo y por sus vínculos con otros focos culturales contemporáneos.

En efecto, aunque la crítica ha llamado la atención sobre el volumen de composiciones satíricas del trovadorismo ibérico, sobre su abundancia en textos dedicados a las invectivas personales (Suitner 1983a: 75) o sobre la preponderancia que en ella alcanza el campo léxico de lo obsceno (Tavani 1986: 194 y 2002: 71; Lanciani/Tavani 1995: 97), ya Marti (1953: 1-40) subrayaba el carácter europeo de la literatura satírica medieval, incluida la gallegoportuguesa, en tanto que Suitner (1983a: 75-85) y Tavani (2002: 68) destacaban los puntos en común que unían la sátira peninsular y la practicada por los cómico-realistas italianos. Esto se debería a que en ambas líricas, al igual que entre los trouvères del norte de Francia, el discurso satírico tomaba como modelo el sirventés occitano, el cual les proporcionaba un sustrato compartido con más capacidad de cohesión que la que ofrecía la sátira mediolatina, a pesar del prestigio de ésta por su lengua, por su cultivo en medios clericales y escolares y por el auge que había alcanzado en el siglo $\mathrm{XII}^{8}$. No resulta fácil, a su vez, establecer lazos firmes entre la sátira mediolatina y la poesía occitana; antes bien, esta última, como constata Marti (1953: 36-37), se revela distante del espíritu goliardesco que impregna a aquélla. En realidad, la sátira mediolatina apenas habría provisto a las tradiciones trovadorescas de la periferia occitana con una serie de tópicos, que a menudo no serían sino parte de un fondo retórico común que podía rastrearse ya en la poesía romana. Por ejemplo, las apelaciones de la poesía mediolatina a la vida marginal, a la afición a las mujeres, el vino y el juego, que con tanta fortuna retomaron los sonetos de Cecco Angiolieri o los versos de Martin Soarez (vid. B1358

\footnotetext{
${ }^{8}$ Mann (1993: 73) y Thomson (1978) consideran el siglo XII como el del auge de la sátira latina, al que siguió la eclosión de la sátira en vulgar.
} 
/ V966), son todos ellos topoi de larga tradición, de los que, por ejemplo, se había servido ya Juvenal. Igual que son tópicas las apelaciones a la Fortuna y sus caprichos, la misoginia, la atribución de determinados defectos a ciertos grupos sociales o las burlas a costa de la vejez, que, además, se encuentran no sólo en la poesía, sino también en la narrativa -los fabliaux-o el teatro.

Algún otro rasgo que se ha considerado singular de la sátira gallegoportuguesa merece también una consideración de conjunto en el marco de la poesía cortés. Es lo que sucede, por ejemplo, con la escasez de cantigas políticas del corpus de escarnio y maldecir, que, según el repertorio métrico de Tavani, apenas alcanzan las veintitrés composiciones (vid. Tavani 1967), en tanto que $M e d D B$ sube su producción a treinta. Su volumen, tenido por escaso, ha suscitado la necesidad de explicaciones, las cuales se han fijado en las estructuras sociales de la Península Ibérica y la ausencia en la misma de un sistema de cortes señoriales como el occitano, que garantizase el imprescindible margen de libertad expresiva. En la Península, a pesar de que en la fase de implantación trovadoresca algunas cortes señoriales florecieron como centros de irradiación lírica, éstas carecerían de fuerza como para que se consolidase ese tipo de poesía. Tavani (2002: 72), por ejemplo, estima que apenas un par de cortes del noroeste ibérico, la gallega de los Traba y la portuguesa de los Sousa, habrían ejercido como verdaderos núcleos rectores de la experiencia poética, pero sólo durante los años iniciales. Aun sin excluir la existencia de cortes señoriales que continuasen como focos de irradiación poética en una época posterior, ese papel lo asumirían sobre todo las cortes regias portuguesa y castellanoleonesa, lo que habría provocado la escasez de sátiras políticas. Y esto explicaría, también, que el autor del que más composiciones de esa especie se hayan conservado sea precisamente un monarca, Alfonso X, de quien se nos han transmitido ocho de esas cantigas?.

Aun así, no toda la poesía política gallegoportuguesa cabe en los márgenes estrechos que parecen sugerir esos datos. El ciclo de cantigas sobre los nobles portugueses que traicionaron a Sancho II, por ejemplo, demostraría que esa idea de un poder central con capacidad de monopolio sobre la enunciación poética puede matizarse en algunos aspectos. Quienes alzan la voz en esas cantigas son justo los perdedores del conflicto, por más que D. Sancho hubiese contado con el apoyo del entonces infante Alfonso ${ }^{10}$ y de que buena parte

\footnotetext{
${ }^{9}$ Según la clasificación de $M e d D B$, otros autores que cultivaron la poesía política fueron Airas Perez Vuitoron, trovador gallego integrado en la corte de Alfonso X, con tres cantigas de este tipo, y dos trovadores portugueses establecidos en Castilla tras el derrocamiento de Sancho II, Gil Perez Conde, con cuatro, y Pero Gomez Barroso, con tres piezas.

${ }^{10}$ No así con el de Fernando III, que evitó que Castilla y León participase en el conflicto portugués (González Jiménez 2004-2005: 21-22). Calderón Medina (2013), explica que Alfonso y parte de la noble-
} 
de los contrarios al Boloñés encontrasen en Castilla refugio y, se supone, el medio adecuado desde donde lanzar sus invectivas contra el nuevo monarca. Pero aun si en este caso se considera este ciclo de cantigas bajo la alargada sombra de Alfonso X y su uso de la poesía con fines propagandísticos, no se puede decir lo mismo de aquellas piezas, como las de Gil Perez Conde o Alfonso Fernandez Cubel, en las que un trovador se queja del trato que recibe por parte del rey, que, por la posición de su destinatario, trascienden la simple crítica personal ${ }^{11}$. En fin, aun cuando Ora faz ost'o senhor de Navarra, el célebre maldizer de Johan Soarez de Paiva, se nos aparece hoy en día como un ejemplo hasta cierto punto aislado y singular, reflejaría la importancia que la sátira política y de actualidad habría asumido en las primeras fases del trovadorismo peninsular ${ }^{12}$.

Con todo, no pasa desapercibido el contraste que, a pesar de la cantiga de Soarez de Paiva, se muestra entre la lírica gallegoportuguesa y su modelo occitano. Por ejemplo, la producción que en ambas tradiciones poéticas se dedica al fecho del Imperio, que ha estudiado Alvar ${ }^{13}$, ofrece una elocuente disparidad entre el silencio casi absoluto que al respecto mantienen los trovadores ibéricos, solo roto por la tensón Ay Pedr'Amigo, vós que vos tẽedes (B323 / V1550) entre Johan Vazquiz de Talaveira y Pedr'Amigo de Sevilha, y la vehemencia con la que occitanos e italianos intervinieron con sus composiciones en dicho asunto, a menudo en favor del monarca castellano. Y esta intensidad en el debate político se extiende al conjunto de la lírica occitana, en donde la llegada del siglo XIII contempla el triunfo del sirventés político, frente a los síntomas de agotamiento de la poesía amorosa (Aurell 1994: 183). No en vano, los cinco grandes temas sobre los que, según De Riquer (1975: I, 57), tratan este tipo de sirventeses -la reconquista española, la guerra albigense, los conflictos en Italia, la disputas entre Francia y Aragón y las cruzadas a Tierra Santa- se sitúan total o parcialmente durante esa centuria. Lo que esto sugiere es que el trovadorismo d'oc no sólo no decayó con la cruzada albigense y el supuesto desmantelamiento de las cortes señoriales (Paden 2000: 24-25), sino que la inestabilidad que se inició poco después de

za leonesa y gallega intervinieron para defender sus intereses en el reino vecino, en peligro por el cambio de monarca, y por solidaridad familiar con los linajes afectados por la guerra.

${ }^{11}$ Tales cantigas son B1522, B1523 B1524, B1525, B1532 y B1531. De estas, al menos B1532 y, posiblemente B1522 irían dirigidas a Sancho IV. Sobre la posibilidad de que la pieza de Fernandez Cubel (B1610 / V1143) fuese dirigida a Alfonso X, vid. Beltran (2006-2007: 177-179).

${ }^{12}$ Alvar (2002: 57) destaca la importancia de los sirventeses políticos para la importación peninsular del modelo trovadoresco.

${ }^{13}$ Alvar (1984), en donde se alude a Guilhem de Montanhagol, Raimon de Tors, Perceval Doria, Bertran d'Alamanon, Monte Andrea o Cerveri de Girona, entre otros. 
1200 habría impulsado la composición de poesías satíricas de tema político y la consolidación del género del sirventés (Grossel 2004: 4).

Ahora bien, el indudable peso que el modelo occitano ejerció para la aclimatación de la lírica cortés en la Península puede provocar cierto desenfoque si se usa para, a través de él, valorar la poesía gallegoportuguesa. Es lo que sucede, por ejemplo, cuando se aplican inapropiadamente categorías poéticas occitanas a la realidad ibérica, como sucede con el propio sirventés (vid. Lapa 1966: 172 y ss.). La supuesta escasez de poesía peninsular de tema político no escapa a esta consideración, pues las conclusiones que se extraen de esta circunstancia son en parte matizables si la perspectiva se abre a otras tradiciones poéticas coevas. La lírica d'oül, por ejemplo, si bien es verdad que supera el volumen de composiciones políticas de la gallegoportuguesa, ni de lejos alcanza el de la occitana, ni tampoco su diversidad de temas. Grossel (2004: 20-49), de hecho, sólo distingue tres ciclos de poesía política entre los trouvères: las canciones de cruzada, que suman veintinueve composiciones en la recopilación de Bédier y Aubry (1974); el ciclo sobre la sucesión del condado de Champaña y contra la regente Blanca de Castilla; y las disputas entre los estamentos sociales de Arras, cuyas canciones, de indudable variedad temática y formal, pertenecen ya a un ámbito urbano y cuyos protagonistas son clérigos y burgueses. A estas piezas satíricas, en fin, Grossel añade alguna otra sobre conflictos en Inglaterra bajo el reinado de Enrique III o sobre la conquista de Namur por Enrique III de Luxemburgo. En cualquier caso, las conclusiones que se extraen del corpus de poesía política se pueden hacer extensivas al conjunto de la producción satírica d'oïl, para la que es posible postular una rarificación en comparación con el referente occitano. El norte de Francia, pues, no aclimató ni el vers ni el sirventés meridionales, de ahí que el vocablo serventois, por lo demás poco empleado, designase piezas que eludían los temas de actualidad y que, por contra, abordaban los morales o religiosos -como el serventois couronné de los puys poéticos de las ciudades del noreste, dedicados a la Virgen-. Al igual que la poesía política escasea entre los trouvères, tampoco existió entre ellos un género especializado en la sátira -la fuerza subversiva de la sotte-chanson y de la fatrasie se sustentaría en la reducción del discurso al absurdo con fines humorísticos (ThiolierMéjean 1994: 304-307)-, la cual se aleja del modelo trovadoresco, se acerca a la sátira mediolatina e impregna los géneros didácticos, líricos o narrativos, que cultivaron autores como Rutebeuf, Hélinand de Froidmont o, inclusive, los integrantes de los círculos poéticos de Arras, tal que Baude Fastoul, Jean Bodel o Adam de la Halle (Formisano 1994: 96). No extraña, entonces, que 
Bec (1977) no encontrase un acomodo para la sátira en su clasificación por géneros de la lírica d'oïl.

De todo lo cual se concluye que entre los trouvères el registro satírico no está contenido en un género, como entre los occitanos, sino que se manifiesta disgregado en varios de ellos, que además se sitúan fuera del modelo poético trovadoresco. Y tal circunstancia también se ha entendido como fruto de una cierta anomalía, tal es el peso que sobre la crítica ejerce la lírica occitana como referente, de ahí que se haya buscado una explicación ad hoc. Sin embargo, en este caso mal sirve el argumento de la centralización de la actividad poética en las cortes regias, puesto que el norte de Francia conformaba un territorio de gran complejidad política, en el que el poder monárquico convivía con estados señoriales y, sobre todo a partir del siglo XIII, con regiones dotadas de un alto grado de desarrollo urbano. Aun así, la explicación que da Zaganelli (1982: 11-23) -como sucedía con las que se ofrecen para la lírica gallegoportuguesa- se fija en las estructuras políticas de esa región. Para este autor, en tanto que la zona bajo influencia de la dinastía Capeta no mostró interés por la actividad poética de los trouvères, ésta sí que arraigó en Flandes y Champaña, dos regiones que se habrían mantenido al margen del proceso de desintegración institucional que siguió al colapso del poder carolingio. Eso les evitaría los problemas políticos y militares que derivaron de esa crisis institucional, al tiempo que habrían conseguido mantener viva una red de cortes que se beneficiaron de un precoz despegue económico. Mientras, París y su entorno, bajo el control de la monarquía, favorecían otras manifestaciones culturales dedicadas a la promoción de la ideología regia.

Pero más llamativo aún es el caso de la ausente producción satírica entre los poetas sicilianos, ya fuese esta de tema político, moral o personal ${ }^{14}$. Al plantearse una situación de nuevo análoga a la que se ofrece para la lírica gallegoportuguesa, los intentos de explicación para esta carencia no han dejado de resaltar los paralelos que pudiesen existir entre una y otra tradición lírica, siendo el más aducido aquel que apela a las semejanzas en el sistema de organización política y social sobre el que se sustentaba a su vez el sistema literario. Como en la Península, en Sicilia el poder centralizado en el emperador Federico II y su Magna Curia habría impedido la libre expresión de las disputas, en especial las políticas, por medio de la poesía. Cuánto más que Federico era el único promotor de dicha escuela lírica, de manera que su figura aglutinaba en su entorno -como promotor, pero también como poetaa los autores que la cultivaban, quienes a menudo desempeñaban cargos en

\footnotetext{
${ }^{14}$ Aunque sí es cierto que, como indica Brugnolo (1995: 299), entre los sicilianos se encuentran algunos poemas, bien que excepcionales, de tema moral y doctrinal.
} 
el entramado administrativo de su corte (vid., por ejemplo, Antonelli 1994; Krauss 1982: 132-133).

La distancia entre las estructuras sociales del mundo feudal occitano, en el que surgió la lírica trovadoresca, y el grado de centralización estatal sobre el que se organizaba la Sicilia Hohenstaufen resulta demasiado evidente como para que se le niegue, cuando menos, una parte de verdad a una explicación de este género. Con todo, un análisis detenido de las circunstancias que concurren en el desarrollo de la poesía siciliana descubre ciertos aspectos matizables en tal propuesta. Uno de ellos se refiere a la familiaridad de Federico II con los trovadores en lengua $d^{\prime} o c$, quienes lo mencionan en más de cuarenta composiciones en lengua occitana ${ }^{15}$, buena parte de las mismas apoyándolos a él y a sus descendientes en sus conflictos con el Papado y los franceses. El supuesto desapego de Federico -o incluso su oposición- por la poesía política queda también en entredicho al considerar una figura como Percevale Doria, cuyas composiciones de este tema-Felon cor ai et enic y Per aquest cors, del teu trip- utilizan el occitano, mientras que sus poesías amorosas Come lo giorno quand'è dal matino y Amore m'avè priso-, que se acogen al canon siciliano, optan por el italiano. Su bilingüismo poético sería fruto de una especialización lingüística (Brugnolo 1995: 295), que recuerda a la que practicó Alfonso X, con su preferencia por el gallegoportugués para la lírica y el castellano para la prosa, o en la misma línea en que se expresan las Razos de trobar cuando recomiendan una lengua específica para cada género lírico: «La parladura francesca val mais et [es] plus avinenz a far romanz et pasturellas, mas cella de Lemosin val mais per far vers et cansons et serventes. E per totas las terras de nostre lengage son de maior autoritat li cantar de la lenga lemosina qe de neguna autra parladura» (Marshall 1972: ms. B, 7) ${ }^{16}$. De los datos anteriores se concluye que no es que Federico II prohibiese el cultivo de la poesía política, sino simplemente que esta no se expresó en italiano. Y el único factor que determinó esa elección fue la existencia de otras lenguas de mayor prestigio o que ya estaban consolidadas con anterioridad en ese registro, como el occitano, el griego o el latín. En consonancia con la teoría de los estilos, que vinculaba el tema tratado en un texto con el registro lingüístico empleado, a esos dos últimos idiomas se les adjudicó la labor de promoción cultural y política del estado federiciano, en tanto que al vulgar italiano se le

${ }^{15}$ Meliga (2005: 855) identifica cuarenta y cuatro piezas que se dirigen o aluden a Federico II.

${ }^{16} \mathrm{El}$ texto del ms. $H$ coincide añade algún otro género a ese elenco: «Per que deves saber que la parladura francesa val mays e es pus avinent a far romanç e retronxas e pastorellas, et aycellas de Lemosi valon mays a cansos, a serventes, a verses. E per totas las terras del nostre lengatge son en maior auctoritat li cantar de la parladura de Lemozi que de null'autre» (Marshall 1972: ms. H, p. 7). 
relegó a una función diletante y menos trascendente, como la poesía amorosa (Grimaldi 2016: 72-78 y 2017: 190-194; Meliga 2005: 865).

La inexistencia entre los sicilianos de un género que desempeñase las funciones del sirventés occitano conllevó que la poesía correspondiente al genus demonstrativus retórico se limitase al intercambio polémico de sonetos o tenzoni, que aun así se especializaron en cuestiones literarias y de casuística amorosa. Pero dicho retraimiento no es exclusivo a los sicilianos y afecta al conjunto de la poesía italiana del Duecento. Incluso aunque el panorama político de, por ejemplo, la Toscana, se pareciese más al occitano que al de la centralizada Sicilia imperial, los poetas toscanos se interesaron menos por la poesía política que por la moral (Grimaldi 2009: 102; Stefanini 1995: 165). Es por esto que las explicaciones aducidas, que apelan a circunstancias particulares de la corte siciliana, se antojan insuficientes. Aparte de una posible pérdida en la transmisión textual italiana por selección estilística, provocada por el peso del canon estilnovista - lo que la condenaría a una transmisión oral y efímera- (Grimaldi 2009: 92-96), un fenómeno como el de la escasez de poesía política quizá deba relacionarse con algún otro factor de naturaleza poética, tal que la simplificación generalizada del sistema de géneros líricos en la poesía en italiano, no sólo la siciliana. De acuerdo con Picone (2000: 149-150), la lírica italiana avanzó, durante el siglo XIII, hacia una homogeneización de los géneros, que perdieron su autonomía y su especificidad para integrarse en un nuevo macrogénero, el canzoniere -o libro di poesia-, basado en la construcción de un relato sobre la vida del poeta en su doble vertiente de artista y amante. Es el molde que explora Guittone d'Arezzo -mientras en la lírica occitana hacía algo parecido Guiraut Riquier (Bertolucci 1989: 87124) - y en el que profundizan Dante y Petrarca. Más cuestionable se presenta la supuesta desaparición en la poesía italiana de la oposición canso - sirventés, sobre la que giraba la poética occitana, debido, según este estudioso, al abandono del sirventés por parte de los poetas toscanos, no por el desinterés por sus temas, sino por su tratamiento sub specie amoris (Picone: 2000: 148).

En realidad, la innegable simplificación del sistema lírico en Italia no renuncia a la dupla canso - sirventés, si bien se redefine bajo los nuevos principios compositivos que imponen el triunfo de una forma poética formalmente fija, como el soneto, y consideraciones en torno a los niveles de estilo y los temas poetizables, como las que sistematizará Dante (De vulgari eloquentia, II, 2, 7-8; vid. Suitner 1983b). Cierto es que la poesía política italiana se adapta a la realidad urbana y a los valores burgueses de su contexto de producción, apartándose de la exaltación bélica que se identifica con el espíritu caballeresco que encarnan los sirventeses de Bertran de Born, pero no por ello dejó 
de cultivarse, en especial tras la inestabilidad que sucedió a la muerte de Federico II, la cual impulsó a los autores italianos a polemizar sobre asuntos de actualidad, ya no sólo en occitano, sino también en vernáculo (Borsa 2011: 155). Sin embargo, esa vertiente de la sátira que es la poesía política ha recibido una atención relativamente escasa por parte de la crítica, en buena medida, como apunta Borsa (2011: 149), por la influencia que sobre la misma ha ejercido el canon poético que Dante establece en De vulgari eloquentia, en donde niega la poesía política entre los italianos - «Arma vero nullum latium adhuc invenio poetasse» (II, 2, 10; Rovira Soler y Gil Esteve 1982: 130)-, o en Il convivio, donde ni siquiera contempla este tipo de composiciones.

Minimizar la relevancia que la poesía política, y la sátira en general, alcanzan en la segunda mitad del siglo XIII entre los autores del centro y el norte de Italia -con independencia del número de composiciones que ha sobrevivido en los cancioneros-, al igual que tratarla como una realidad separada de la lírica amorosa, como si los denominados autores cómico-realistas o incluso los propios estilnovistas no hubiesen cultivado ambas modalidades, implica que se obvie la producción polémica de un autor como Monte Andrea y la importancia que, por su militancia güelfa, tiene en ella el debate político; o que se soslaye que estilnovistas como Cino da Pistoia o el propio Dante se interesaron por la poesía de tema cívico. Dicha separación explica que, por ser compositor de piezas satíricas y amorosas al estilo siciliano, de Rustico Filippi se destaque la «bifronte maestria» (Marti 1953: 45), calificación que recuerda las perplejidades causadas por la obra de Guilhem de Peitieu.

De hecho, amor y política son dos realidades indeslindables, que, además, buscan puntos de contacto más intensos que el simple cultivo por parte de los mismos autores. Si tal premisa ya se cumplía en la lírica occitana, debido a la reutilización por el sirventés de los esquemas métricos y melódicos de la canso o a la confluencia de ambos registros en el sirventés-canso, en la italiana se manifiesta en el despliegue, en la poesía política, de topoi del registro amoroso. Por ejemplo, el tratamiento de la ciudad patria como una mujer amada, cuyo alejamiento, por causa del exilio, provoca el mismo dolor que el de los amantes que se separan, que aparece en Gravosa dimoranza de Guglielmo Beroardi, en donde la ambigüedad que así se crea produce también un doble sentido de lectura (Bartuschat 2005: 96-98). O, también, en S'eo son distretto inamoratamente de Brunetto Latini y en su respuesta Amor quando mi membra de Bondie Dietaiuti, que funcionarían como canto de amistad o de añoranza por la ciudad de Florencia ${ }^{17}$. Lo cual concuerda con la observación

${ }^{17}$ El sentido político de la canción de Brunetto fue defendido por Rossi (1997: 13-14). 
de Folena (1970: 30) de que la lírica florentina de tema político se valió del lenguaje amoroso, pero también con la de Lubello (2008: 531), de que ambos temas se funden en textos en los que se juega con el doble sentido. Más ejemplos se podrían aducir sobre esta intersección de los discursos amoroso y político en un mismo poema, lo que confirmaría el arraigo de dicho recurso entre los poetas italianos, como, quizá, Avegna che partensa de Bonagiunta Orbicciani, que insistiría en el motivo de la partida (Marcenaro 2017: 57-58), o Dogliosamente e con gran malenanza de Inghilfredi da Lucca, a la que Borsa (2011: 164) califica de «vera e propria canso-sirventés».

Este modo de componer se ha explicado como fruto del proceso de subjetivización del discurso lírico italiano (Marcenaro 2017: 67), si bien no hay que olvidar que una situación análoga se plantea entre los trouvères (Formisano 1994: 95). Por ejemplo, en la obra de Adam de la Halle, quien en Arras ki ja fus se refiere a su ciudad como si fuese una dama que ya ha entrado en declive -y piénsese en su reutilización del topos del declive femenino causado por la edad en el Jeu de la Feuillée-. Otros poetas de Arras actúan de forma parecida y retoman elementos de la lírica amorosa para sus sátiras, como aquellas que, en la línea de lo expuesto, oponen la juventud a la vejez (Dane 1984: 123-124). E idéntico procedimiento compositivo se rastrea en la lírica gallegoportuguesa. Sobre este particular llama la atención Beltran (20062007: 170 y ss.), quien reinterpreta una serie de cantigas satíricas que, bajo la apariencia de ataques personales, sirven de cauce de expresión a conflictos políticos. De esa forma, una cantiga como Citola oi andar-se queixando de Alfonso X (B488 / V71) aludiría, no a las demandas de un juglar impertinente, sino a las reclamaciones de los nobles que se rebelaron contra el rey entre 1271 y 1272. Se relacionaría, entonces, con Non troux'estes cavaleiros aqui de Gil Perez Conde (B116), con Un ricome que oj'eu sei de Pero Gomez Barroso (B1443 / V1054) y, tal vez, incluso con alguna cantiga de Airas Perez Vuitoron -Don Martin Galo est'acustumado (B1483 / V1094)- o con las sátiras de Pero da Ponte contra nobles avarientos. Un procedimiento análogo lo emplearía Don [E]stevam, oi por vós dizer de Pedr'Amigo de Sevilha (B1660 / V1194), que se vale del motivo amoroso de la mujer guardada para atacar a Esteban Fernández de Castro, quien, durante esa revuelta nobiliaria, había criticado al monarca por retener a Aldonza Rodríguez, su prometida. Este mismo personaje, en fin, podría ser el mismo Fernan Diaz Escalho, al que dirigen sus burlas poéticas un grupo de trovadores del círculo alfonsí1 ${ }^{18}$.

${ }^{18}$ Vid. asimismo Beltran (2000). Los autores que se refieren a este personaje serían Airas Perez Vuitoron, Estevan Faian, Pero da Ponte, Pero Garcia Burgalês, Pero Garcia d’Ambroa y Roi Paez de Ribela. 
La perspectiva que abren estas claves interpretativas nos pone ante una situación semejante a las lecturas en dos niveles que se proponía en poesías políticas italianas contemporáneas, como las mencionadas más arriba. Según Beltran (2006-2007: 184), la sátira política gallegoportuguesa, salvo excepciones, evitaba la exposición directa de sus planteamientos y se enmascaraba a menudo bajo la forma de invectivas personales, el tipo de sátira más abundante en la lírica trovadoresca peninsular. Ahora bien, puesto que las cantigas anteriores se escriben en los medios poéticos favorables a Alfonso X, ¿tiene sentido, entonces, sugerir que el corpus de escarnio gallegoportugués rehúye la sátira política a causa del monopolio enunciativo de la corte regia, cuando era de esa misma corte de donde emanaban más a menudo tales ataques y cuando su cabeza, el rey mismo, atacaba a sus adversarios indistintamente por medio de mensajes directos o indirectos? No menos dudas se suscitan sobre las razones de su proceder a la vista de otros dos ejemplos, más conocidos, en que un asunto político se cubre con los ropajes del discurso amoroso. Se trata de las dos cantigas que Gonçal'Eanes do Vinhal compuso a causa de la enemistad entre Alfonso X y su hermano, el infante don Enrique, en las que, con la apariencia de cantigas de amigo, una voz femenina pide noticias de su amigo y alude a su expulsión del reino -Amigas, eu oy dizer (B1390 / V999) y Sey eu, donas, que deytad'é d'aqui (V1008)-. ¿Fue la capacidad coercitiva de Alfonso X la que influyó para que ambas composiciones evitasen la exposición directa de su mensaje, velándolo con los tópicos del registro amoroso? En tal caso, la dificultad interpretativa menguaría la función comunicativa de los textos, lo que cuestionaría su eficacia, mientras que, en el supuesto de que dicha coacción no se produjese, resultaría ociosa, de acuerdo con esa lógica, la adopción de la cantiga de amigo.

Los datos que proporcionan las cantigas satíricas antes mencionadas, así como la utilización de recursos expresivos afines en otras tradiciones líricas restan validez a la tesis de un supuesto control de la corte regia castellana sobre los debates políticos expresados por cauces poéticos. No se olvide que el cultivo en Italia de poesías satíricas sub specie amoris se llevaba a cabo en un contexto en el que existían varios bandos en conflicto, sin que ninguno de ellos fuese capaz de condicionar las facultades enunciativas de sus adversarios. A la vista de la aparición de métodos compositivos afines en tradiciones líricas con trasfondos socio-culturales dispares, más bien habría que pensar en que dichas poesías políticas adoptaban tal proceder obedeciendo a principios asentados sobre factores estéticos, antes que pragmáticos, sobre cuyo peso por idéntico motivo en la poesía italiana advertía Grimaldi (2009: 93 y 112) que la mayoría de las cantigas explícitamente políticas que se han conservado 
sean obra de Alfonso X quizá respondiense a la exclusión de los cancioneros por ese criterio de ese tipo de poesía explícita, habiéndose salvado las del Rey Sabio, justo por la categoría de su autor-. Así, dicho procedimiento compositivo podría relacionarse con el prestigio que rodeaba al registro amoroso, que se refleja en la centralidad que, desde que se consolidó como forma poética entre los occitanos, en la segunda mitad del siglo XII, ocupaba la canso en el sistema de géneros líricos. La apropiación por el sirventés de los esquemas formales de cansos previas, por tanto, no sería sino un mecanismo que contribuyese a la dignificación de la sátira. Pero asimismo habría que considerar el peso que el discurso amoroso adquirió en las tradiciones líricas periféricas, es decir, en Italia, entre los gallegoportugueses y los trouvères. En esta última tradición, sin ir más lejos, la escasa atención concedida en el sistema genérico a la poesía de circunstancias se compensó con la mayor importancia dada a los géneros popularizantes (Formisano 1994: 97), análoga a la que le prestó la lírica peninsular. Pero sobre todo, y teniendo presente el ya citado prestigio de la canción amorosa, sería decisiva la capacidad de ésta de imponer un alto grado de isomorfismo en el conjunto de la producción poética ibérica, hasta el punto de que su impronta se habría dejado sentir en otros géneros, con el consiguiente efecto de nivelación estilística. Un ejemplo de este fenómeno lo representarían los lais de Bretanha y su acercamiento al molde de la cantiga de amor-Mui gran temp'á, par Deus, que eu non vi (B3 / L3)-o a la bailada -O Maroot aja mal grado (B2 / L2), Ledas sejamos ogemais (B4 / L4)-, género este, por cierto, asimilado a su vez a la cantiga de amigo ${ }^{19}$.

A pesar del desgaste que la canción de amor sufre durante el siglo XIII -recuérdense las estadísticas de Paden-, no por ello dejaría de ocupar un papel central en la configuración de los sistemas líricos que se iban perfilando según maduraba la experiencia trovadoresca. Eso explicaría, por ejemplo, que tanto en las artes poético-gramaticales occitanas, como en el Arte de trovar gallegoportuguesa, la canción amorosa encabece los elencos de géneros. La imposición de sus formas sobre las composiciones satíricas italianas aludidas reflejaría asimismo la función legitimadora que seguía manteniendo. De la sátira italiana se ha destacado (Marti 1953: 1-40; Suitner 1983a: 75-85), precisamente, su parecido con la gallegoportuguesa, pues, aunque abarcaba temas variados, en ella tienen un peso considerable la invectiva personal, la crítica de tipos sociales y el vituperium (Bisiacco-Henry 1994). Sin embargo,

${ }^{19} \mathrm{Vid}$., por ejemplo, la consideración como cantigas de amigo de B881 / V464 y B879 / V462, ambas de Airas Nunez; de B115bis / V761 de Johan Zorro; o de B735 / V336 de Pero Viviaez por parte de Lopes (s. f.) y $M e d D B$. Esta última base de datos, que trata la bailada como un motivo de la cantiga de amigo, incluye asimismo entre este tipo B1283 / V889 / N6 de Martin Codax. 
tanto el menor valor artístico que se daba a ese tipo de poesía, como sus limitaciones comunicativas -pues, al vincularse su elaboración a circunstancias concretas, su sentido se perdía con rapidez- habrían propiciado ciertos cambios en la misma. Los occitanos se inclinaron por aumentar en la sátira el peso del componente moral y didáctico, de acuerdo con una transformación impulsada por el modelo de sirventés que había establecido Bertrand de Born (Asperti 2004 y 2005), de tal forma que la superación de la sátira centrada en el ataque personal singularizó una parte cada vez más importante de la producción satírica de esa tradición lírica más allá de 1200. Tal es la opción que siguieron autores como Peire Cardenal o Guilhem de Montanhagol. El didactismo moralizante conllevaba una apertura del enfoque crítico de las poesías, que así abandonaban las cuestiones particulares que afectaban a individuos concretos, para fijarse en problemas generales. La difusión de estas piezas se ligaría entonces a la defensa de valores universales, lo que garantizaba su pervivencia más allá de la función propagandística que se adjudicaba a la poesía de circunstancias, cuya existencia solía ser muy precaria (Grimaldi 2009: 96). Grossel (2004: 46), por ejemplo, advierte de que el sirventés se consideraba un género de menor valor que la canso y, también, de que, ya antes de que se fijasen sus rasgos distintivos como género, por ser poesía satírica y de circunstancias, salvo el caso aislado de las moralidades latinas, sus composiciones estaban destinadas a una rápida desaparición. Tal es, recuerda Aurell (1994: 187), lo que habría sucedido con los sirventeses que se compusieron entre 1255 y 1285 en favor de los descendientes de Federico II, de los que, justo por su difusión oral, apenas si se ha conservado una veintena, es decir, una pequeña parte de lo que debió de ser la producción total. El nuevo modo de poetizar, por contra, se asentaba con más firmeza en una base escrituraria, sobre la que se desplegaban los recursos retóricos del código cortés, al tiempo que establecía vínculos más directos con las letras latinas (Beltran 2011: 81-115). La eficacia de la transformación que se operó en el paradigma genérico occitano permitió que la poesía satírica se convirtiese en uno de los mecanismos de renovación de la lírica tardía, uno de cuyos frutos más sólidos fue la recuperación del vers y su especialización como pieza moral.

También en la Península Ibérica la sátira se habría visto afectada por las corrientes renovadoras que se extendían por las otras tradiciones líricas. Pero en este caso el camino seguido no dejó de ser paradójico. En vez de impulsar la composición de cantigas morales, a cuyo tímido y tardío despertar ya nos hemos referido, y en lugar de impregnar con estilemas amorosos las cantigas satíricas, éstas se sometieron al proceso inverso y alteraron, no su componente formal, sino el contenido. El resultado serían esas cantigas en las que, bajo 
la apariencia de ataques personales que buscaban el escarnio y la burla por defectos físicos o de conducta, se deslizaban censuras más severas y trascendentes, como las que afectaban a los conflictos políticos. En cuanto a por qué el trovadorismo ibérico optó por un sentido literal en el que, lejos de inclinarse por una forma prestigiosa, como la de la canción amorosa, se mostraba, de manera sorprendente, la invectiva y el viturperium, quizá habría que tener en cuenta aspectos como el conservadurismo de la tradición lírica peninsular, que propiciaba un mayor apego a formas expresivas que en otras tradiciones se estaban cuestionando. Acaso influyese la renuencia a introducir mudanzas drásticas en un sistema poético no cerrado a las innovaciones, pero que las asumía sin rupturas. Puede que la adhesión a la invectiva personal fuese una forma de preservar la centralidad de la cantiga de amor, considerada el género más aristocrático, por el procedimiento de mantener su carácter exclusivo sin que asumiese ninguna otra función, mientras evitaba el riesgo de que el registro amoroso y el satírico diluyesen sus límites, por el procedimiento de que este último se apropiase del aspecto formal del primero. Esta última situación resultaba mucho más arriesgada que la que planteaban los textos paródicos -los denominados escarnios de amor y de amigo-, ya que la parodia se basa, no en la similitud, sino en las diferencias entre dos términos de comparación. No en vano, en los textos paródicos siempre se acaba por hacer explícita su naturaleza burlesca.

El mérito de dichas cantigas, entonces, no estaría en asumir una cobertura tenida por prestigiosa, sino en articular un mensaje con dos sentidos, uno evidente y otro implícito, en el que este segundo sólo estaba al alcance de los conocedores de las claves necesarias para su adecuada descodificación. Todo ello en consonancia con la poética de la obscuritas, tan cara a los medievales, cuyo modelo más conocido es el de los diversos modos de interpretación textual $^{20}$, el cual, por su elitismo, hacía de la exigencia y la iniciación una garantía para la preservación de la verdad. En efecto, si ya Agustín ponderaba el esfuerzo y el placer cognitivos precisos para acceder a verdades que no se mostraban abiertamente (Antonelli 2004: 48-49; Marrou 1938: 483-490), en la Crónica abreviada don Juan Manuel alabará el ocultamiento del saber, al que imagina cercado por muros que impiden el acceso a los necios (Blecua 1983: 573). Pero ya antes, los occitanos habían encarecido las virtudes de la paraula escura, concebida como una expresión densa en significados que había que descifrar. Aunque la poética de la obscuritas tiene un representante temprano en Marcabru, fue Peire d'Alvernha quien la formalizó en la

\footnotetext{
${ }^{20}$ Además del clásico de De Lubac (1959-1964), vid. Irvine (1964: 254-255), quien advierte de que no se trataría en sí de niveles de significado textual, sino de modos de clasificar el significado.
} 
doctrina del trobar clus, a la que luego se adherirán trovadores como Guiraut de Bornelh, Raimbaut d'Aurenga o Gavaudan (Zambon 2004: 98-102). El primero, por ejemplo, destacaba «Que sens e cartatz / Adui pretz e dona» (28, vv. 23-2; Sharman 1989: 168), mientras que el último, con intenciones elitistas, vinculó grado de oscuridad y modelo de lector: «Mos sens es clars als bos entendedors, / Trop es escurs a selh que no sap gaire» (8, vv. 10-11; Guida 1979: 340; vid., Landoni 1989: 30). Esta declaración, como se verá de seguido, no deja de recordar a algún pasaje del Arte de trovar del cancionero $B$, pues, en el fondo, el camino adoptado por la sátira gallegoportuguesa, que culmina en la mirada retrospectiva de esa arte poética tardía, buscaba fines similares a los que, por otras vías procuraron occitanos e italianos; es decir, el descubrimiento de significados velados por un lenguaje polisémico.

Aunque la tradición exegética sobre la que se sustentaba la poética de la oscuridad textual había elaborado modelos sumamente complejos en el despliegue de modos de interpretación, el que gozó de más difusión distinguía cuatro -literal, alegórico, tropológico y anagógico-. En su formulación más sencilla los sentidos textuales se reducían a dos, que remitían a la idea del velo (integumentum o involucrum) ${ }^{21}$ que cubría un contenido (Tauste Alcocer 1995). Esta doctrina, de raíces tanto clásicas como patrísticas, se difundió en la Edad Media a través de la interpretación y la glosa de la Biblia y de los textos latinos, a los que se supuso un sentido filosófico oculto que los convertía en aceptables para el pensamiento cristiano. Pero la literatura en lengua vulgar también aceptó la idea de la cubrición de significados bajo el ornato que proporcionaban los recursos de la elocutio. Si bien las alusiones a este procedimiento compositivo son innumerables en la literatura de la época -como numerosas son las referencias que al mismo hace Juan Ruiz en el Libro de buen Amor, cuya obra se convierte en un juego de sentidos ambiguos (vid. Torres-Alcalá 1990)-, pocas declaraciones son tan certeras como la que expone Santillana en su Prohemio e carta, donde se refiere a la «muy fermosa cobertura» con que en poesía se cubrían las cosas útiles (Gómez Moreno 1990: 52). No hace falta recordar, en fin, que esos principios compositivos, basados en la existencia de dos niveles de sentido, corresponden a las indicaciones que proporciona el Arte de trovar del cancionero $B$ acerca de las cantigas de escarnio, que los emplearían frente a las cantigas de maldecir:

${ }^{21}$ Con todo, y de acuerdo con la observación de Marciano Capella, el integumentum era una variedad del involucrum, que se definía como un discurso que bajo un relato fabuloso ocultaba un sentido verdadero. La otra variedad de involucrum era la allegoria, es decir, un discurso en el que un relato histórico acogía un sentido verdadero, pero diferente del sentido superficial. El primero se aplicaría a los textos seculares, mientras que el segundo sería propio de los textos sagrados (Gersh 2001: 92-93; Mora-Lebrun 1994: 105-106). 
Cantigas d'escarneo som aquelas que os trobadores fazen querendo dizer mal d'alguen en elas, e dizen-lho por palavras cubertas que hajan dous entendimentos, pera lhe-lo nom entendere... ligeiramente; e estas palavras chaman os clérigos «hequivocatio». [...] Cantigas de maldizer son aquel $<$ as $>$ que fazem os trobadores $<$ contra alguem $>$ descubertamente: e $<$ em $>$ elas entrarám palavras $\mathrm{e}<\mathrm{m}>$ que queren dizer mal e nom aver $<$ ám $>$ outro entendimento se nom aquel que querem dizer chãam<ente $>$ (Tavani 1999: 42).

Contra la tentación de extraer conclusiones a partir de las indicaciones que ofrece el Arte de trovar se opone su redacción en la fase final del lirismo gallegoportugués, pues en realidad dicho tratado proyectaba una mirada retrospectiva y parcial que no siempre era fiel a la realidad poética del inicio y el apogeo trovadorescos (Beltran 2011: 93-94; Tavani 1999: 26). No obstante, y aun de modo tardío, la definición de las cantigas de escarnio -y quizá su propia consideración como género independiente- a partir del encubrimiento de sus contenidos revela una voluntad de dignificación de dicho género por el recurso de vincularlo con los círculos clericales. Es así que la asociación de la polisemia, a la que apunta el redactor anónimo con la expresión «dous entendementos», y la idea de ocultamiento por medio de un integumento remite a los procedimientos exegéticos de textos latinos, que habían cobrado nuevo impulso durante el siglo XII y que se mantenían vivos aún en el XIV (Jeauneau 1973: 176). En concreto, la vinculación de la equivocatio con los sentidos ocultos que crea el involucrum, desvelables por medio de la exégesis, la recoge, por ejemplo, el Commentum super Eneidos de Bernardo Silvestre, quien explica que un mismo integumento podía designar realidades diferentes y, al revés, una misma realidad podía expresarse por medio de varios integumenta: «Notandum est hoc in loco, quemadmodum in aliis misticis voluminibus, ita et in hoc equivocationes et multivocaciones et integumenta ad diversa respicere» (apud Jeauneau 1973: 135). Frente al concepto de ambigüedad, que suponía una relación horizontal de significados en conflicto, el integumento establecía un vínculo vertical, que además de evitar la confusión de significados, enriquecía el contenido del discurso (Gersh 2001: 92; Godman 2000: 236). El mismo autor concedía la posibilidad de que los poetas, en especial los satíricos, albergasen en sus escritos propósitos serios (O’Donnell 1962: 238), aunque no hay que olvidar que sus observaciones estaban pensadas para los autores latinos y, aún no, para los escritores en vulgar.

Lo anterior indica que el equívoco del Arte del trovar no correspondería a los dobles sentidos de simples juegos de palabras, al modo de los eufemismos 
sexuales de tantas cantigas gallegoportuguesas o de los casos de mot equivoc que analizan las Leys d'Amors, sino que apunta a un sistema hermenéutico basado en la descodificación de textos con más de una lectura y con significados ocultos bajo una cobertura en apariencia clara e inteligible. Este uso de palabras encubiertas como factor que peculiariza el escarnio, por lo demás, ha provocado no pocas perplejidades en la crítica (vid. Lapa 1965: x), por cuanto no se condice con la praxis textual de los cancioneros gallegoportugueses, en la que ambas modalidades satíricas, el escarnio y el maldecir, conforman una única sección cancioneril. Tampoco el correspondiente aparato paratextual aporta datos concluyentes, de forma que semeja improbable que, al aplicar dicho criterio siguiendo las indicaciones de las rúbricas, se llegue a una distinción coherente entre ambos tipos de sátira ${ }^{22}$; no en vano, la mayoría de las didascalias optan por una etiqueta doble, es decir, imprecisa ${ }^{23}$. Las dudas de que dicho criterio fuese operativo en alguna fase del trovadorismo peninsular parece verse apoyada por el hecho de que los tratados poético-gramaticales occitanos lo desconozcan en sus descripciones de los géneros líricos. Más aún, ninguno de ellos dividió el registro satírico en dos modalidades, sino que mantuvieron la concepción amplia del mismo, que englobaba las funciones del genus demonstrativum de la retórica clásica, las cuales comprendían tanto la alabanza como la crítica ${ }^{24}$. Así, la Doctrina de compondre dictatz establece que el sirventés «deus parlar de fayt d'armes, e senyalladament o de lausor de senyor o de maldit o de qualsque feyts qui novellament se tracten» (Marshall 1972: 95) 25; y de manera parecida se expresan el Tratado de Ripoll ${ }^{26}$ y las Leys d'amors, cuya redacción larga, que destaca el componente moral de la sátira, precisa, no obstante, que «deu tractar de reprehensio o de mal dig general, per castiar los fols e los malvatz, o pot tractar, qui $\cdot \mathrm{s}$ vol, del fag d'alguna guerra», e insiste: "Tractans de maldig general, / Per castiar cels que fan mal, / o de fag mantas vetz de guerra» (Fedi 2019: 373 y 381). Precisamente por su variedad, Thiolier-Méjean (1978: 38) concluye que no

${ }^{22}$ Las cantigas calificadas como de escarnio por las rúbricas son: B144, B1367 / V975 y B1369, V977. Las de maldecir, por su parte son: B1330bis / V937, B1334 / V941, B1351 / V958, B1352 / V959-960, B1357 / V965, B1389 / V998, B1470 / V1080 y B1477 / V1088.

${ }^{23}$ En caso se encontrarían las rúbricas que acompañan a: B1360 / V968, B1361 / V977, B1441 / V1051, B1510, B1512, B1513, B1543, B1561, B1619 / V1152, B1621 / V1152, B1621 / V1153, B1622 / V1155, B1627 / V1161.

${ }^{24}$ Vid. Dagenais (2000: 245 y ss.), en donde dicho principio se hace extensivo al conjunto del sistema de géneros occitanos.

${ }^{25}$ Más adelante insiste: «deu parlar de senyors o de vassalls, blasman o castigan o lauzan o mostran, o de faytz d'armes o de guerra o de Deu o de ordenances o de novelletatz» (Marshuall 1972: 97).

${ }^{26}$ «sua materia es de tot ço qui $\cdot s$ pot dir o per alscuns afers assanyalats, axi con per host o per aveniment de rey o per prleso d'alcun loch, o per castich d'alcuna persona o per semblan cosa» (Marshall 1972: 101). 
es el tema el que define como género al sirventés, sino su reutilización de esquemas métrico-melódicos. Se trata de la misma concepción amplia que guió a los compiladores cancioneriles ibéricos, cuando reunieron en la sección de escarnio y maldecir a todas las cantigas que no pertenecían al registro amoroso, convirtiéndola en un cajón de sastre a ojos de la crítica (Lanciani/ Tavani 1995: 8).

Por otra parte, el análisis de las alusiones metapoéticas de las cantigas se enfrenta a las conocidas vacilaciones que a menudo presenta la terminología medieval. Tres son los trovadores de época alfonsí que de forma evidente aluden en sus textos a las cantigas satíricas: Airas Perez Vuitoron, Pero da Ponte y Gonçal'Eanes do Vinhal. En Joan Soárez, pero vós teedes (B1481 / V1092), Vuitoron polemizaba con Johan Soarez Coelho, indicándole los dos modos de componer que él reconocía como correctos: «ca ben trobamos d'escarnh'e d'amor» (v. 12, Lapa 1965: 137). El pasaje, a pesar de que designa dos modos de trovar identificables con sendos géneros de cantigas, no despeja las dudas acerca de si alude a géneros concretos, de si a escarnho hay que darle un sentido amplio, referido al registro satírico en general, o incluso de si tales términos no serían sino etiquetas temáticas. La cautelas se hacen más necesarias cuando esa alusión se relaciona con otras dos semejantes: una procede de Maestre, todo'lus vossos cantares (V1007), en la que Eanes do Vinhal criticaba a un tal maestre Nicolás, que se apropiaba y destrozaba las cantigas ajenas: «D'amor e d'escarnh'en todas razões / os seguides sempre» (16, vv. 8-9: Víñez Sánchez 2004: 256); y otra se encuentra en la Cantiga de Santa María $\mathrm{n}^{\circ} 316$, cuyo protagonista era «crerigo trobador, / que sas cantigas fazia d'escarn[o] mais ca d'amor» (vv. 15-16) (Mettmann 1986-1989: III, 133). Contra la impresión, que se desprende de las cantigas anteriores, de que existiese un sistema binario que sólo identificase composiciones amorosas y satíricas, sin distinciones internas, se erige Sueir'Eanes, nunca eu terrei ( $B 1650$ / V1184), en la que Pero da Ponte ${ }^{27}$ ataca a otro mal poeta que se arriesgaba a ser blanco de cantigas satíricas, a las que se denomina como cantares de maldecir: «se de mal trobador enmentan i, / que vós logo non digades: - A min / foi feit'aquel cantar de mal dizer» (vv. 19-20; Panunzio 1992: 193). El propio Pero da Ponte habría compuesto un poema infamante contra Sueiro Eanes, según confiesa en Sueyr'Eanes, nunca eu terrey (B1650 ( V1184), lo que confirmaría que los versos anteriores aluden a un tipo de cantiga. Finalmente, la posibilidad de que existiesen dos modalidades en el registro satírico a mediados del siglo xIII podría verse refrendada de manera

${ }^{27}$ Si bien Sueiro Eanes habría vivido al menos hasta 1269 (vid. De Lollis 1887: 31-66), Panunzio sitúa el ciclo de cantigas sobre su persona bajo el reinado de Fernando III (Panunzio 1992: 34). 
indirecta por Rodrigu'Ianes, queria saber (V1032), tensón entre Lourenço y Rodrigu'Eanes Redondo, en la que aquél acusa a su interlocutor de que «a vós nunca vos vimos fazer / cantar d'amor nen d'amigo» (vv. 4-5; Lapa 1965: 406), aunque sólo sea porque la duplicidad de géneros en el registro amoroso parece propiciar, por analogía, un desdoblamiento también en el campo de la sátira' ${ }^{28}$; o incluso por Hun cantar novo d'amigo de Pedr'Amigo de Sevilha (B1214 / V819), cuya mención a esa variedad del canto amoroso confirma su existencia como género independiente ${ }^{29}$.

Pero, aun admitiendo ese sistema simétrico de géneros -con las tensós, como contrapunto dialogado-, no por ello hay que admitir, insistimos, el criterio por el que el Arte de trovar separa el escarnio y el maldecir, que bien pudo elaborarse, como otras normas de dicho tratado, a partir de la reinterpretación a posteriori de los textos poéticos. Y es que la escisión satírica que en él se propone no responde al significado de los términos que designan cada modalidad, ya que el maldecir envía a las poesías infamantes que se componían para la deshonra pública de alguien, mientras que el escarnio abarca el ámbito de las burlas y el humor no necesariamente ofensivo ${ }^{30}$. Salvo, claro está, que se apele a la exigencia de claridad de la crítica infamante y al mayor margen de libertad verbal de las bromas asociadas al escarnio, aunque este tipo de explicaciones, basadas en los recursos de la elocutio, corre el riesgo de situar las cantigas trovadorescas al nivel de los cantos infamantes, cayendo en el mismo error que si se considerasen poesías populares las cantigas de amigo.

Tal vez arrojen luz a este panorama tan incierto las rúbricas que califican ciertas composiciones como maldecires apostos, ya que, a pesar de su escaso número ${ }^{31}$, suponen una alteración en el esquema binario del escarnio y el maldecir. Puesto que el adjetivo aposto designa algo bien hecho y realizado convenientemente, su atribución añade un sentido valorativo, desde

\footnotetext{
${ }^{28}$ También alude a los cantares de maldecir Rui Gonçalviz, pero vos agravece (B1312 / V917), en la que Estevan da Guarda acusa a uno de sus protagonistas de «trobar de mal dizer» (v. 5; Lapa 1965: 180) contra otro mal trovador. No obstante, Estevan da Guarda es un trovador tardío, cuya actividad poética se dataría ya en el xIv.

${ }^{29} \mathrm{~A}$ todas ellas se pueden añadir las alusiones a cantares de amor (B639 / V240, B969 / V556, B1357 / V965, B1573, B520bis), trovar de amor (A279, B872 / V456) y aun a cantigas de amor (B1173 / V77). $\mathrm{Su}$ capacidad probatoria es menor, porque podrían referirse al canto amoroso en general y no a una modalidad específica así designada.

${ }^{30}$ No solo en las cortes ibéricas se compondrían cantigas que no había que tomar en serio, por tratarse de bromas poéticas (vid. Menéndez Pidal 1991: 207-208. Según Dane (1984: 125), las burlas de Adam de la Halle a sus conciudadanos, los burgueses de Arras, en sus poemas o en el Jeu de la Fenillée eran aceptadas con agrado por estos, que las consideraban un signo de reconocimiento social.

${ }^{31}$ Sólo seis cantigas se califican de esa manera: cinco de Martin Soarez -B1358 / V966, B1363 / V971, B1364 / V972, B1365 / V973 y B1366 / V974- y una de Lopo Lians -B1350 / V975-.
} 
una perspectiva estética, a las cantigas así señaladas. Y esto, a pesar de su consideración como maldecires y de que, una vez más, resulta difícil saber por qué se adjetivó así esas cantigas en concreto y no otras, pues todas ellas parecen consistir en burlas, literarias las de Martin Soarez y personal la de Lopo Lians -aunque sabidas son las implicaciones políticas de ciertas burlas de ese trovador (Beltran 2011: 13-35)-. En cualquier caso, tales didascalias apuntan a una voluntad de hacer del maldecir algo más que una simple invectiva, dotándolo de una dignificación artística. Quizá sea en exceso arriesgado aventurar que la legitimación de esa clase de cantigas satíricas abrió una vía que llevó a la distinción propuesta por el Arte de trovar, pero puede que no lo sea tanto pensar que tales rúbricas están relacionadas con el establecimiento de un tipo de sátira que fuese aceptable en el marco conceptual de la lírica cortés y acaso, el reconocimiento de dos categorías en su interior, según el grado de la violencia verbal y la habilitación de recursos elocutivos adecuados a cada una de ellas.

Una conclusión a las reflexiones anteriores apunta, por tanto, hacia la inserción de la sátira alfonsí, y la gallegoportuguesa en general, en el contexto de las corrientes poéticas de su época. Por encima de las particularidades que se puedan destacar en la sátira peninsular, ésta se acerca a otras tradiciones contemporáneas, tanto por su repertorio como por el uso de recursos compositivos. Así, el lugar privilegiado que en ella se otorga a las invectivas personales no excluye el cultivo de otros temas, como las diatribas políticas, los debates literarios o, aunque más esporádicamente, la crítica moral. No sólo eso, las propias invectivas personales gozaron de una estimación parecida en la poesía cómico-realista italiana, mientras que los trovadores occitanos, bien que de manera más restringida, tampoco renunciaron al registro anticortés ${ }^{32}$ o a la polémica literaria, impregnada de crítica social, con los juglares. Algo semejante se puede decir, como hemos visto, del recurso a una poética de la obscuritas, que obliga a revisar la adscripción temática de no pocas cantigas satíricas gallegoportuguesas y a replantearse algunos de sus principios compositivos, que envían a procedimientos que asimismo se rastrean entre los poetas italianos y los trouvères.

La peculiaridad más notoria de la sátira ibérica no se encontraría entonces en el plano temático, sino en la distinción entre dos modalidades, en lo que se opone al carácter omnicomprensivo del sirventés occitano y a la ausencia de una forma específica para la sátira en las líricas italiana y d'oül. Ante la confusión que suscita el uso de las etiquetas de escarnio o maldecir en las rúbricas

${ }^{32}$ Vid. la recopilación de Bec (1984), que reúne hasta cincuenta composiciones. 
cancioneriles, y teniendo en cuenta que éstas habrían comenzado a redactarse en el último cuarto del siglo XIII (Lorenzo 2003: 117-118), cuando algunos textos podían no ser ya bien comprendidos (Lagares 2000: 67), se suele sostener que la sátira gallegoportuguesa avanzó hacia una indistinción de dos modalidades diferentes en su origen. Estaríamos entonces ante los ecos de una integración tardía en el código cortés de antiguos cantares maledicentes, toda vez que los cantares de escarnio, por su componente lúdico, parecerían aceptar una asimilación menos problemática a dicho código. Las que aparecen registradas en los cancioneros son, claro está, cantigas trovadorescas y no cantos de maldecir; pero acaso haya que pensar que tal designación para un puñado de ellas reflejaría ese carácter más arcaizante del trovadorismo peninsular, el mismo que se manifestaba en la pervivencia mayoritaria en dicha tradición lírica de un modelo de sátira más apegada a formas tradicionales y renuente a adoptar los nuevos modos de poetizar que durante el siglo XIII estaban arraigando entre los occitanos. Quizá no sea una casualidad, en fin, que tres de las cinco cantigas rubricadas como de maldecir sean ataques políticos (B1330bis / V937; B1470 / V1080, B1477 / V1088), precisamente aquel tipo de piezas que, como demostró De Riquer (1973), gozaban de una difusión más eficaz, aunque efímera, porque eran las que mejor se adecuaban a «dizer mal d'alguen en elas».

Ahora bien, ese supuesto proceso de indistición y fusión de las modalidades satíricas describe justo la evolución contraria que estaba produciéndose en otras tradiciones líricas, como la del norte de Francia o, sobre todo, la occitana, en las que la experimentación con nuevos géneros, y su consiguiente multiplicación, configuraban una de las principales vías de renovación del trovadorismo tardío. La obra de Cerveri ejemplifica esto último, mientras que el prolijo elenco genérico de las Leys d'Amors lleva al extremo esa búsqueda de modalidades textuales inéditas. No en vano, las reflexiones sobre esas modalidades -a las que podemos calificar de géneros líricos- son una novedad que se desarrolla a lo largo del siglo XIII -y las artes poéticas occitanas son testimonio de ello-, impulsadas por la difusión del aristotelismo y por la exigencia de métodos de clasificación textual, que se vinculaban con los procesos de compilatio y ordinatio que triunfaban desde el siglo XII, así como con el que Hamesse (2011) denomina como el modelo escolástico de lectura. A la luz de este último condicionante, las alusiones textuales y metatextuales gallegoportuguesas -nótese que las más tempranas no remontan más allá del período de floración de Alfonso X-habría que interpretarlas como los intentos, aún incipientes, de consolidar un registro satírico doble, bajo criterios todavía no bien perfilados -posiblemente diferentes a los que usará el Arte de 
trovar-, lo que profundizaría en la renovación del arte poética en concordancia con otras áreas del Occidente medieval. Reflejo de esto último podría ser, en fin, la composición por autores de la segunda mitad del siglo XIII e inicios del XIV, de modalidades como la pastorela, la bailada o la cantiga de telar ${ }^{33}$. Que la corte alfonsí haya sido el espacio idóneo para emprender esa renovación de la lírica ibérica es más que probable, a la vista de su papel como principal catalizador de la experiencia trovadoresca en su fase de esplendor.

\section{Referencias bibliográficas}

Alfonso X (1807), Las siete partidas del Rey Don Alfonso el Sabio, cotejadas con varios códices antiguos por la Real Academia de la Historia. Tomo tercero, Partida Quarta, Quinta, Sexta y Séptima. Madrid: Imprenta Real. Alvar, Carlos (1977), La poesía trovadoresca en España y Portugal. Madrid: CUPSA.

Alvar, Carlos (1984), «Poesía y política en la corte alfonsí», Cuadernos Hispanoamericanos, 410, pp. 5-20.

Alvar, Carlos (2002), «Política y poesía: la corte de Alfonso VIII (...11581214)», Mot, So, Razo, 1, pp. 52-61.

ANTONELLI, Roberto (2004), «Oscurità e piacere», en Giosuè Lachin y Francesco Zambon (eds.), Obscuritas: retorica e poetica dell'oscuro. Atti del XXIX Convegno Interuniversitario di Bressanone (12-15 luglio 2001). Trento: Università di Trento, pp. 47-58.

AntonelLI, Roberto (1994), «La scuola poetica alla corte di Federico II», en Pierre Toubert y Agostino Paravicini Bagliani (eds.), Federico II e le scienze. Palermo: Sellerio, pp. 309-323

ASPERTI, Stefano (2004), «L'éredità di Bertran de Born», Cultura Neolatina, 64:3-4, pp. 475-525.

ASPERTI, Stefano (2005), «El sirventes i l'herència de Bertran de Born», Mot, So, Razo, 4, pp. 49-58.

ASPERTI, Stefano (2006), «Generi poetici di Cerveri de Girona», en Vicenç Beltran, Meritxell Simó y Elena Roig (eds.), Trobadors a la Península Ibèrica. Homenatge al Dr. Marti de Riquer. Barcelona: Publicacions de l'Abadia de Montserrat, pp. 29-71.

${ }^{33}$ MedDB identifica como pastorelas B868 / V454 de Airas Nunez; B534 / V137, B519 / V102 y B547 / V150 de Don Dinis; B967 / V554 de Johan Airas de Santiago; B676 / V278 de Johan Perez de Aboim; B1148a / V751 de Johan Zorro, B1262 / V867 de Lourenço; y B1098 / V689 de Pedr'Amigo de Sevilha. Como bailadas, B881 / V464 y B879 / V462 de Airas Nunez; B1158bis / V761 de Johan Zorro; B1283 / V889 / N6 de Martin Codax; B735 / V336 de Pero Viviaez; y dos lais de Bretanha, B5 y B2. Como cantiga de telar B720 / V321 de Estevan Coelho. 
Aurell, Martin (1994), «Chanson et propagande politique: les troubadours gibelins (1255-1285)», en Paolo Cammaronsano (ed.), Le forme della propaganda politica nel Due e nel Trecento. Relazioni tenute al convegno internazionale di Trieste (Trieste, 2-5 marzo 1993). Roma: École Française de Rome, pp. 183-202.

BARTUSCHAT, Johannes (2005), «Thèmes moraux et politiques chez quelques poètes florentins pré-stilnovistes: une hypothèse de recherche», Arzanà. Cahiers de Littérature Médiévale Italienne, 11, pp. 87-103.

Bertolucci-Pizzorusso, Valeria (1966) «La Supplica di Guiraut Riquier e la rispossta di Alfonso X di Castiglia», Studi Mediolatini e Volgari, 14, pp. 387-405.

Bertolucci-Pizzorusso, Valeria (1989), Morfologie del testo medievale. Bologna: Il Mulino.

BEC, Pierre (1977), La lyrique française au Moyen Âge: XII ${ }^{e}$-XIII ${ }^{e}$ siècles. Contribution à une typologie des genres poétiques médiévaux. Paris: J. Picard.

BEC, Pierre (1984), Burlesque et obscénité chez les troubadours: pour une approche du contre-texte médiéval. Paris: Stock.

Beltran, Vicenç (2000), «Esteban Fernández de Castro y Fernán Díaz Esca1lo», Madrygal. Revista de Estudios Gallegos, 3, pp. 13-20.

Beltran, Vicenç (2006-2007), «Trovadores en la corte de Alfonso X», Alcanate, 5, pp. 163-190.

Beltran, Vicenç (2011), La creación de una lengua poética: los trovadores entre oralidad y escritura. Alessandria: Edizioni dell'Orso.

Bisiacco-Henry, Nella (1994), «L'invective dans la poésie comico-réaliste italienne», Atalaya. Revue Française d'Études Médiévales Hispaniques, 5, pp. 85-100.

Blecua, José Manuel (ed.) (1983), Don Juan Manuel, Crónica abreviada, en Don Juan Manuel. Obras completas. Madrid: Gredos, pp. 505-815.

BÉDIER, Joseph y Pierre Aubry (1974), Les Chansons de croisade, avec leurs mélodies. Genève: Slatkine.

Borsa, Paolo (2011), «Poesia d'armi e poesia politica dalle Origini a Dante», en Paolo Grillo (ed.), Cittadini in armi: eserciti e guerre nell'Italia comunale. Seminario di studi, Milano, 11 giugno 2009. Soveria Manelli: Rubbettino, pp. 141-195.

BRUgnolo, Furio (1995), «La Scuola poetica siciliana», en Enrico Malato (dir.), Storia della Letterature Italiana, t. I, Dalle Origini a Dante. Roma: Salerno Editrice, pp. 265-337.

CABRÉ, Miriam (1996), «“Ne suy juglars ne·n fay capteniments”: l’offici de trobador segons Cerverí de Girona», en Jacques Gourc y François Pic 
(eds.), Toulouse à la croisée des cultures. Actes de VE Congrès International de l'Association Internationale d'Études Occitanes (AIEO). Toulouse, 19-24 août 1996. Paris: Association Internationale d'Études Occitanes, t. I, pp. 211-224.

CALDERón Medina, Inés (2013), «La solidaridad familiar. La participación de la nobleza leonesa en la guerra civil de Portugal (1245-1247)», Hispania, 73, pp. 617-646. DOI: https://doi.org/10.3989/hispania.2013.016.

CANetTieri, Paolo y Carlo Pulsoni (1994), «Para un estudio histórico-xeográfico e tipolóxico da imitación métrica na lírica galego-portuguesa. Recuperación de textos trobadorescos e troveirescos», Anuario de Estudios Literarios Galegos, pp. 11-50.

Cantigas de seguir. Modelos Occitânicos e Franceses. En línea: $<$ https://cantigas.fcsh.unl.pt/contrafacta.asp> [consulta: 13/02/2021]

Dagenais, John (2000), «Genre and Demonstrative Rhetoric: Praise and Blame in the Razos de trobar and the Doctrina de compondre dictats», en William. D. Paden (ed.), Medieval Lyric: Genres in Historical Context. Urbana/Chicago: University of Illinois Press, pp. 242-254.

Dane, Joseph A. (1984) «Parody and Satire in the Literature of ThirteenthCentury Arras, Part II», Studies in Philology, 81:2, pp. 119-144.

De Lollis, Cesare (1887), «Cantigas de amor e de maldizer di Alfonso el Sabio re di Castiglia», Studi di Filologia Romanza, 2, pp. 31-66.

De Lubac, Henri (1959-1964), Exégèse médiévale. Les quatre sens de l'écriture. Paris: Aubier.

Fedi, Beatrice (2019), Las Leys d'Amors. Redazione lunga in prosa. Firenze: Edizioni del Galluzzo.

FolenA, Gianfranco (1970), «Cultura poetica dei primi fiorentini», Giornale Storico della Letteratura Italiana, 147, pp. 1-42.

Formisano, Luciano (1994), «La poesia lirica», en Costanzo Di Girolamo (ed.), La letteratura romanza medievale: una storia per generi. Bologna: Il Mulino, pp. 62-125.

GERSH, Stephen (2001), «Cratylus mediaevalis - Ontology and polysemy in medieval platonism (to ca. 1200)», en John Marenbon (ed.), Poetry \& Philosophy in the Middle Ages. A Festchrift for Peter Dronke. Leiden/Boston/ Köln: Brill, pp. 79-98.

Godman, Peter (2000), The Silent Masters. Latin Literature and Its Censors in the High Middle Ages. Princeton: Princeton University Press.

Gómez Moreno, Ángel (ed.) (1990), Íñigo López de Mendoza, Marqués de Santillana. El Prohemio e carta de Santillana y la teoría literaria del s. XV. Barcelona: PPU. 
GonZÁLEZ JimÉnEZ, Manuel (2004-2005), «Alfonso X y Portugal», Alcanate, 4, pp. 19-34.

Grimaldi, Marco (2009), «Politica in versi. Manfredi dai trovatori alla Commedia», Annali dell'Istituto Italiano per gli Studi Storici, 24, pp. 79-167.

GRIMALDI, Marco (2016), «La réception de la poésie politique des troubadours en Italie», Revue des Langues Romanes, 120, pp. 69-87.

GRIMALDI, Marco (2017), «La poesia storico-politica dai trovatori alla Scuola siciliana», en Paolo Di Luca y Marco Grimaldi (eds.), L'Italia dei trovatori. Roma: Viella, pp. 179-195.

Grossel, Marie-Geneviève (2004), «Quand le monde entre dans la chanson. Chansons politiques, chansons de croisade, serventois et autres tensons de trouvères», Cahiers de Recherches Médiévales et Humanistes, 11, DOI: $<$ https://doi.org/10.4000/crm.1863>.

GuIDA, Saverio (1979), Il trovatore Gavaudan. Modena: STEM/Mucchi.

HAMESSE, Jacqueline (2011), «El modelo escolástico de lecura», en Guglielmo Cavallo y Roger Chartier (dirs.), Historia de la lectura en el mundo occidental. Madrid: Taurus, pp. 145-164.

Irvine, Martin (1994), The Making of Textual Culture. 'Grammatica' and Literary Theory, 350-1100. Cambridge: Cambridge University Press.

JEAUNEAU, Édouard (1973), «L'usage de la notion d'integumentum à travers les gloses de Guillaume de Conches», en Lectio philosophorum. Recherches sur l'École de Chartres. Amsterdam: A. M. Hakke, pp. 127-192.

Krauss, Henning (1982), «Sistema dei generi e scuola siciliana», en Carlo Bordoni (ed.), La pratica sociale del testo. Scritti di sociologia della letteratura in onore di Erich Köhler. Bologna: CLUEB, pp. 123-158.

Lagares, Xoán Carlos (2000), E por esto fez este cantar. Sobre as rúbricas explicativas dos cancioneiros profanos galego-portugueses. Santiago de Compostela: Laiovento.

Lanciani, Giulia y Giuseppe Tavani (1995), As cantigas de escarnio. Vigo: Xerais.

LANDONI, Elena (1989), La teoria letteraria dei provenzali. Firenze: Leo S. Olschki.

Lang, Henry R. (2010), Cancioneiro d'El Rei Dom Dinis e estudos dispersos. Niterói: EdUFF.

LAPA, M. Rodrigues (1965), Cantigas d'escarnho e de mal dizer dos cancioneiros medievais galego-portugueses. Vigo: Galaxia.

LAPA, M. Rodrigues (1966), Lições de literatura portuguesa. Época medieval. Coimbra: Coimbra Editora. 
Lopes, Graça Videira, et al. (s. f.), Cantigas Medievais Galego Portuguesas [base de dados online]. Lisboa: Instituto de Estudos Medievais - FCSH/ NOVA, en línea: <http://cantigas.fcsh.unl.pt> [consulta: 1/03/2021].

LoRENZo Gradín, Pilar (2003), «Las Razos gallego-portuguesas», Romania, 121, pp. 99-132.

Lubello, Sergio (2008), «Brunetto Latini, S'eo son distretto inamoratamente (V 181): tra lettori antichi e moderni», en Irene Maffia Scariati (ed.), $A$ scuola con ser Brunetto. Indagini sulla ricezione di Brunetto Latini dal Medioevo al Rinascimento. Atti del Convegno Internazionale di Studi. Università di Basilea, 8-10 giugno 2006. Firenze: Edizioni del Galluzzo, pp. 515-534.

ManN, Jill (1993), «La poesia satirica e goliardica», en Guglielmo Cavallo, Claudio Leonardi y Enrico Menestò (dirs.), Lo spazio letterario del Medioevo. 1. Il Medioevo latino. Vol. I: La produzione del testo. Roma: Salerno Editrice, t. II, pp. 73-109.

MARCENARO, Simone (2017), «Soggettività ed emotività nella poesia realistica medievale: dai trovatori al Duecento italiano», Revista de Cancioneros, Impresos y Manuscritos, 6, pp. 40-71. DOI: https://doi.org/10.14198/ rcim.2017.6.03.

Marrou, Henri-Irénée (1938), Saint Augustin et la fin de la culture antique. Paris: E. de Boccard.

Marshall, John H. (ed.) (1972), The Razos de trobar of Raimon Vidal and Associated Texts. Oxford/London: Oxford University Press.

Marti, Mario (1953), Culture e stile nei poeti giocosi del tempo di Dante. Pisa: Nistri-Lischi.

MedDB. Base de datos da Lirica Profana Galego-Portuguesa (Base de datos da Lírica Profana Galego-Portuguesa (MedDB). En línea: <http://www. cirp.gal/meddb $>$ [consulta: 13/02/2021].

Meliga, Walter (2005), «Trovatori provenzali», en Federico II. Enciclopedia federiciana. Roma: Istituto dell'Enciclopedia Italiana, pp. 854-867.

MenÉndez Pidal, Ramón (1991), Poesía juglaresca y juglares. Madrid: Espasa-Calpe.

Mettmann, Walter (ed.) (1986-1989), Alfonso X, el Sabio. Cantigas de Santa María. Madrid: Castalia.

Mora-Lebrun, Francine (1994), L'«Énéide» médiévale et la naissance du roman. Paris: Presses Universitaires de France.

O'Donnell, J. Reginald (1962), «The Sources and Meaning of Bernard Silvester's Commentary on the Aeneid», Medieval Studies, 24, pp. 233-249. 
PAdEN, William D. (1997), «The Chronology of Genres in Medieval GalicianPortuguese Lyric Poetry», La Corónica, 26:1, pp. 183-201.

PADEN, William D. (2000), «The System of Genres in Troubadour Lyric», en William D. Paden (ed.), Medieval Lyric. Genres in Historical Context. Urbana/Chicago: University of Illinois Press, pp. 21-67.

Panunzio, Saverio (ed.) (1992), Pero da Ponte. Poesías. Vigo: Galaxia.

Paredes, Juan (ed.) (2001), El cancionero profano de Alfonso X el Sabio. L'Aquila: Japadre.

PiCONE, Michelangelo (2000), «Traditional Genres and Poetic Innovation in Thirteenth-Century Italian Lyric Poetry», en William D. Paden (ed.), $M e$ dieval Lyric. Genres in Historical Context. Urbana/Chicago: University of Illinois Press, pp. 146-157.

RIQUER, Martín de (1973), «Il significato politico del sirventese provenzale», en Vittore Branca (ed.), Concetto, storia, miti e immagini del Medio Evo. Firenze: Sansoni, pp. 287-309.

RiQueR, Martín de (1975), Los trovadores. Historia literaria y textos. Barcelona: Planeta.

Rossi, Luciano (1997), «Brunetto, Bondie, Dante e il tema dell'esilio», en Tatiana Crivelli (ed.), Feconde venner le carte. Studi in onore di Ottavio Besomi. Bellinzona: Casagrande, pp. 13-34.

Rossi, Luciano (2002), «Comico e burlesco nelle letterature romanze dei secoli XI-XIII», Studi Mediolatini e Volgari, 47, pp. 33-55.

Rovira Soler, Matilde y Manuel GIL Esteve (eds.) (1962), Dante Alighieri. De vulgari eloquentia. Madrid: Universidad Complutense.

Sharman, Ruth V. (1989), The cansos and sirventes of the troubadour Giraut de Borneil: A critical edition. Cambridge: Cambridge University Press.

Stefanini, Ruggero (1995), «Guittone politico», en Michelangelo Picone (ed.), Guittone d'Arezzo nel settimo centenario della morte. Atti del Convegno internazionale di Arezzo (22-24 aprile 1994). Firenze: Franco Cesati Editore, pp. 165-176.

SuITNER, Franco (1983a), La poesia satirica e giocosa nell'età dei comuni. Padova: Antenore.

SuITNER, Franco (1983b), «Dante e la poesia satirica del suo tempo», Letture Classensi, 12, pp. 61-79.

Tauste Alcocer, Francisco (1995), «El Comentario a la Eneida de Bernardo Silvestre», Daimon. Revista de Filosofia, 10, pp. 23-36.

TaVANI, Giuseppe (1967), Repertorio metrico della lirica galego-portoghese. Roma: Edizioni dell'Ateneo.

TaVANI, Giuseppe (1986), A poesía lírica galego-portuguesa. Vigo: Galaxia. 
Tavani, Giuseppe (1999), Arte de trovar do Cancioneiro da Biblioteca Nacional de Lisboa. Lisboa: Edições Colibri.

Tavani, Giuseppe (2002), Tra Galizia e Provenza. Saggi sulla poesia medieval galego-portoghese. Roma: Carocci.

Thiolier-MÉJean, Suzanne (1978), Les poésies satiriques et morales des troubadours du XII siècle à la fin du XIII ${ }^{e}$ siècle. Paris: A. G. Nizet.

Thiolier-MÉJean, Suzanne (1994), La poétique des troubadours. Trois études sur le sirventes. Paris: Presses de l'Université de Paris-Sorbonne.

Thomson, Rodney M. (1978), «The Origins of Latin Satire in Twelfth Century Europe», Mittellateinisches Jahrbuch. Internationale Zeitschrift für Mediävistik, 13, pp. 73-83.

TORRES-AlCAlá, Antonio (1990), «El Libro de buen amor: corteza y meollo», en Juan Fernández Jiménez, José Julián Labrador Herraiz y L. Teresa Valdivieso (eds.), Estudios en homenaje a Enrique Ruiz-Fornells. Erie (Pennsylvania): ALDEEU, pp. 633-640.

VÍÑEz SÁNCHEZ, Antonia (2004), El trovador Gonçal'Eanes do Vinhal. Estudio histórico y edición. Santiago de Compostela: Universidade de Santiago de Compostela.

Zaganelli, Gioia (1982), Aimer, sofrir, joïr. I paradigmi della soggettività nella lirica francese dei secoli XII e XIII. Firenze: La Nouva Italia.

ZAmBon, Francesco (2004), «Trobar clus e oscurità delle scritture», en Giosuè Lachin y Francesco Zambon (eds.), Obscuritas: retorica e poetica dell'oscuro. Atti del XXIX Convegno Interuniversitario di Bressanone (1215 luglio 2001). Trento: Università di Trento, pp. 91-102.

Recibido: $31 / 03 / 2021$

Aceptado: 24/04/2021 
$\cos$

\author{
LoS GÉNEROS SATÍricos DURANTE EL REINADO DE ALFONSO X \\ EN LA POESÍA GALLEGOPORTUGUESA Y OTRAS TRADICIONES LÍRICAS ROMANCES
}

RESUMEN: El presente trabajo analiza qué características singularizan la sátira trovadoresca gallegoportuguesa respecto a la cultivada en otras tradiciones líricas. La crítica suele identificar esa diferencia en el plano temático, ya que la sátira ibérica cultiva mayoritariamente el vituperium y las invectivas asociadas a ataques personales. Sin embargo, un análisis comparado con las otras tradiciones poéticas muestra que esa circunstancia no constituye una excepción y que, por el contrario, desde el punto de vista temático la lírica gallegoportuguesa posee puntos en común con la poesía europea coetánea, por ejemplo, con la de los poetas cómico-realistas italianos. También coincide con las otras tradiciones líricas en el uso de un lenguaje dotado de dobles sentidos, aunque posiblemente bajo premisas que no coincidan con las que establece el Arte de trovar del cancionero $B$ para distinguir entre las cantigas de escarnio y las de maldizer.

Palabras-Clave: Lírica gallegoportuguesa. Sátira. Trovadores. Lírica occitana. Trouvères. Poesía italiana.

\title{
The SATIRIC GENRES DURING THE REIGN OF ALFONSO X IN THE GALICIAN-PORTUGUESE POETRY AND OTHER ROMANCE LYRICAL TRADITIONS
}

ABSTRACT: This paper studies those characteristics that make the Galician-Portuguese satire singular with respect to that cultivated in other lyric traditions. Critics tend to identify this difference with the main themes treated by the Iberian satiric poetry, because it use profusely the vituperium and the invective associated to personal attacks. However, a comparatistic analysis with the other poetic traditions reveals that this factor is not an exception. On the contrary, from a thematic point of view the Galician-Portuguese lyric have common grounds with the contemporary European poetry; for example, with that of the Italian comico-realistica poetry. The GalicianPortuguese satiric cantigas coincide also in the use of a double meaning poetic language, although it is utilized according to a different criterion that the stablished by the Arte de trovar of the cancionero $B$ for the distinction between the cantigas de escarnio and the cantigas de maldizer.

KeYwords: Galician-Portuguese Lyric. Satire. Troubadours. Occitan lyric. Trouvères. Italian poetry. 